\title{
Correction to: Darcy-Forchheimer flow and heat transfer augmentation of a viscoelastic fluid over an incessant moving needle in the presence of viscous dissipation
}

\author{
S. Sureshkumar Raju' ${ }^{1}$ K. Ganesh Kumar ${ }^{2}$ Mohammad Rahimi-Gorji ${ }^{3,4} \cdot$ Ilyas Khan $^{5}$
}

Published online: 26 March 2019

(C) Springer-Verlag GmbH Germany, part of Springer Nature 2019

Correction to: Microsystem Technologies

https://doi.org/10.1007/s00542-019-04340-3

The original version of the article unfortunately contained an error in Acknowledgements section. Below is the corrected version.

Acknowledgements The authors are Grateful to the Deanship of Scientific Research at King Faisal University for the support under the Grant 186117.

Publisher's Note Springer Nature remains neutral with regard to jurisdictional claims in published maps and institutional affiliations.

The original article can be found online at https:// doi.org/10.1007/s00542-019-04340-3.

\footnotetext{
Ilyas Khan

ilyaskhan@tdt.edu.vn

S. Sureshkumar Raju

ssurapuraju@kfu.edu.sa

K. Ganesh Kumar

ganikganesh@gmail.com

Mohammad Rahimi-Gorji

mohammad.rahimigorji@ugent.be; m69.rahimi@yahoo.com

1 Department of Mathematics and Statistics, College of Science, King Faisal University, P.O. 380, Al Aha 31982, Saudi Arabia

2 Department of Mathematics, SJM Institution of Technology, Chitradurga 577502, Karnataka, India

3 Experimental Surgery Lab, Faculty of Medicine and Health Science, Ghent University, Ghent, Belgium

4 Biofluid, Tissue and Solid Mechanics for Medical Applications Lab (IBiTech-bioMMeda), Ghent University, Ghent, Belgium

5 Faculty of Mathematics and Statistics, Ton Duc Thang University, Ho Chi Minh City, Vietnam
} 